\title{
STUDI ANALISIS STRUKTUR LIVING QUARTER PADA FLOATING PRODUCTION SYSTEM DI PERAIRAN LEPAS PANTAI INDONESIA
}

\author{
Dewa Ketut Surya Pramana ${ }^{1}$, Siti Nurlina ${ }^{2}$, Indra Waluyohadi², M. Taufik Hidayat ${ }^{2}$ \\ ${ }^{1}$ Mahasiswa / Program Studi Sarjana Teknik Sipil Fakultas Teknik / Universitas Brawijaya \\ ${ }^{2}$ Dosen / Jurusan Teknik Sipil Fakultas Teknik / Universitas Brawijaya
}

\begin{abstract}
Offshore Unit is one of vital infrastructure in gas and oil production. There are many kind of offshore structure which use in gas and oil industry, one of it is a Floating Production System. Floating Production System is system where a modified tanker ship uses by the company of gas and oil to process hydrocarbon, nature gas, and oil. Technically FPS is a tanker ship that produce gas and oil nut can not storage directly while producting, that's why there must be another storage ship while the tanker ship producing. In this living quarter structure analysis constitute on structure analysis in transportation condition. In this living quarter structure analysis utilize SAP2000 V.19 software which obtain bigest moment, shear, and axial from 8 different wave direction that accepted by the ship's hull. Output software analysis and manual analysis shown that main steel structure of living quarter capable hold the loads that applied, which is structure load, dead and live load, wind load, and acceleration load.
\end{abstract}

Keywords : structure analysis, living quarter, floating production system, transport condition

\section{PENDAHULUAN}

Offshore Unit merupakan salah satu infrastruktur vital dalam memproduksi minyak mentah dan gas alam tersebut. Berbagai macam struktur offshore yang digunakan dikalangan industri perminyakan dan gas, salah satunya adalah Floating Production System. Floating Production System adalah suatu sistem dari sebuah kapal terapung yang digunakan oleh industri minyak dan gas lepas pantai untuk produksi dan pengolahan hidrokarbon, gas alam, dan minyak mentah. Secara teknis Floating Production System merupakan kapal tanker yang memproduksi minya mentah dan gas alam namum tidak dapat menyimpan langsung hasil produksi tersebut, maka dari itu terdapat kapal penyimpanan lainnya saat produksi tersebut berjalan.

\section{TINJAUAN PUSTAKA}

Living Quarter pada Floating Production System merupakan struktur baja yang berada pada topside kapal didisain dengan konfigurasi frame. Pada Floating Production System ini terdiri dari tujuh lantai, yaitu dari lantai 1 hingga helideck. Desain Living Quarter yang ada pada desain awal akan dianalisa lagi menggunakan dua standar, yaitu standar AISC [1][2][3][4] dan SNI [5], apakah memenuhi kriteria dan bisa digunakan dalam operasional pada kondisi transportasi.

Pembebanan pada struktur dipengaruhi oleh beberapa pembebanan:

- Beban mati yang berasal dari berat struktur sendiri, dan beban dari benda mati dalam struktur itu sendiri.

- Beban hidup yang merupakan beban para pekerja beroprasional pada living quarter.

- Beban akibat lingkungan merupakan beban yang bekerja oleh angin, gelombang, dan gerakan kapal.

- Beban akibat angin bekerja sebagai beban angin statis untuk penyederhanaan analisis.

Faktor beban yang digunakan adalah faktor beban ULS-a yang mengacu pada 
API RP2FPS dengan beban mati sebesar 1.3, beban hidup 1.3, beban lingkungan 0.7

Kontrol kekuatan struktur harus sesuai dengan beban - beban yang bekerja pada struktur tersebut. Nilai yang dijadikan perhitungan merupakan nilai karakteristik beban maupun nilai nominal beban.

Pada profil, momen maksimum yang terjadi harus dipertimbangkan dengan persamaan $\phi M n>M u$.

Pada penentuan momen nominal menurut AISC dan SNI bergantung pada bentuk penampang, apakah itu kompak, nonkompak, dan langsing berdasarkan pada rasio harga lebar-tebal pada Tabel 1.

Tabel 1. Rasio Nilai Lebar-Tebal

\begin{tabular}{|c|c|c|c|}
\hline Element & $\lambda$ & $\lambda \mathrm{p}$ & $\lambda \mathrm{r}$ \\
\hline Sayap & $\frac{b_{f}}{2 t_{f}}$ & $\frac{65}{\sqrt{F_{y}}}$ & $\frac{141}{\sqrt{F_{y}-10}}$ \\
\hline Badan & $\frac{h}{t_{w}}$ & $\frac{640}{\sqrt{F_{y}}}$ & $\frac{970}{\sqrt{F_{y}}}$ \\
\hline
\end{tabular}

Tabel 2. Rasio Nilai Diameter-Tebal

\begin{tabular}{|c|c|c|c|c|c|}
\hline \multirow{2}{*}{$\frac{8}{3}$} & \multirow[b]{2}{*}{$\begin{array}{l}\text { Description of } \\
\text { Element }\end{array}$} & \multirow{2}{*}{$\begin{array}{l}\text { Width } \\
\text { Thick. } \\
\text { noss } \\
\text { Ratio }\end{array}$} & \multicolumn{2}{|c|}{$\begin{array}{l}\text { Limiting Width- } \\
\text { Thickeness Patios }\end{array}$} & \multirow[b]{2}{*}{ Exampie } \\
\hline & & & $\lambda_{\text {feompact| }}$ & $\frac{\lambda}{\text { enencompaci) }}$ & \\
\hline 14 & 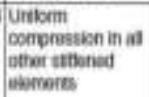 & $\Delta t$ & $\mathrm{NA}$ & $1.0 \sqrt{E T}$ & \\
\hline \multirow[t]{3}{*}{15} & $\begin{array}{l}\text { Comour hotiow } \\
\text { sections }\end{array}$ & & & & \\
\hline & $\begin{array}{l}\text { in unbam } \\
\text { compriasion }\end{array}$ & D, & Na & Q.1TE/F, & \\
\hline & in Reauso & $D / f$ & $0.07 E / F_{Y}$ & $0.3+E j F_{Y}$ & \\
\hline
\end{tabular}

Dimana jika :

nilai $\lambda<\lambda$, penampang adalah kompak nilai $\lambda \mathrm{p}<\lambda \leq \lambda \mathrm{r}$, penampang adalah non kompak nilai $\lambda>\lambda r$, penampang langsing

Untuk tegangan geser persamaan yang digunakan sesuai AISC dan SNI:

$V u<\phi V n=0.6 \phi A w F y w$ dan

$V u<\phi V n=0.6 \phi A g F y$

$A w$ adalah luas penampang badan pada profil WF dan Fyw adalah tegangan leleh penampnag badan dan Ag adalah luas penampang profil untuk profil circular hollow.

Kontrol lendutan ijin dapat digunakan dengan rumus yang dapat dilihat pada Tabel 3.
Tabel 3. Lendutn Ijin

\begin{tabular}{|l|c|c|}
\hline \multirow{2}{*}{ Support Condition } & \multicolumn{2}{c|}{ Allowable Deflection } \\
\cline { 2 - 3 } & Live Load & Dead + Live Load \\
\hline Ends supported & L/360 & L/240 \\
\hline Cantilever & L/240 & L/180 \\
\hline
\end{tabular}

Pada analisis berdasarkan SNI sama seperti analisis dalam perencanaan AISC, hanya saja pelambangan simbol yang berbeda.

\section{METODE ANALISIS}

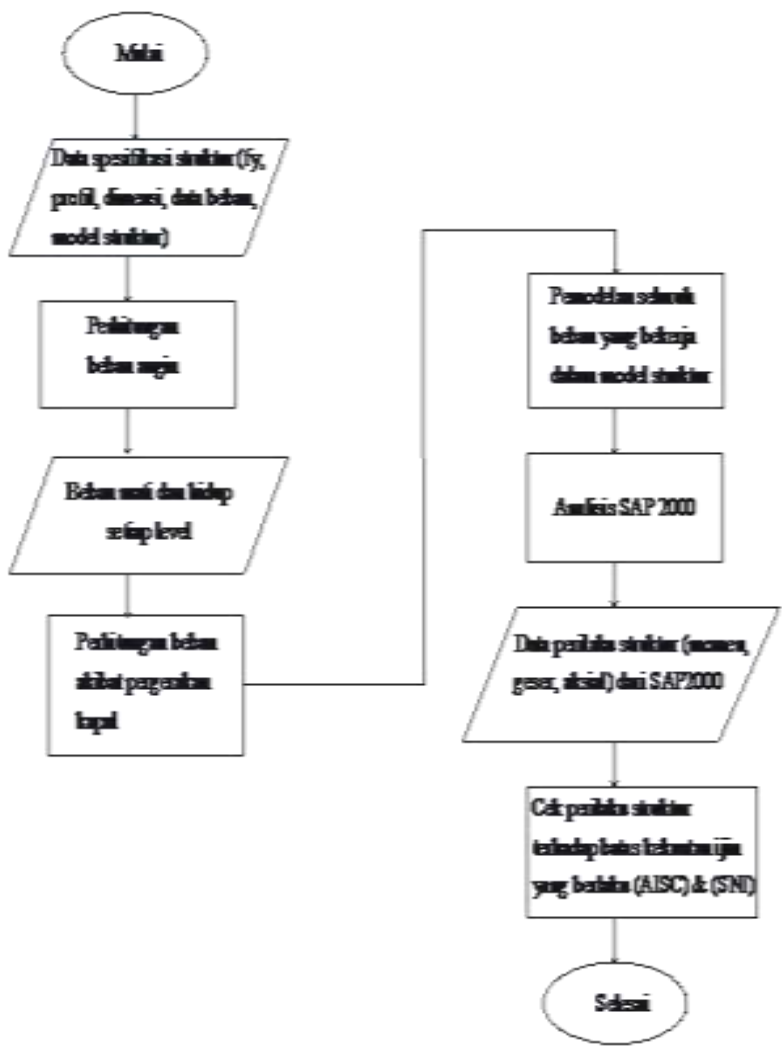

Gambar 1. Diagram Alir Penelitian

\subsection{Data Bangunan}

Bangunan

: Modul Living Quarter pada FPS (Floating Production System)

Lokasi Bangunan : FPS (Floating Production System) di perairan lepas pantai Indonesia.

Jenis Struktur : Struktur baja frame.

Luas Bangunan $: \pm 819 \mathrm{~m}^{2}$

Tinggi Bangunan : $\pm 31.4 \mathrm{~m}^{2}$

Panjang Living Quarter (as ke as) $\quad: 42 \mathrm{~m}$

Lebar Living Quarter (as ke as) : $19.5 \mathrm{~m}$

Tumpuan : Sendi

Sambungan : Las

Untuk profil yang dipakai adalah HE800A, HE650A, HE500A, IPE500, IPE400, IPE300, IPE240, CHS800 $\varnothing \times 40, \quad$ CHS800 $\varnothing \times 20$, 
CHS457Øx15.8,

CHS324Øx12.7, CHS324Øx9.8, CHS273 Øx9.2, CHS219 Øx10, PG790-1, PG790-2, PG790-3.

\section{PEMBAHASAN}

\subsection{Pembebanan Beban Angin}

Program SAP 2000 mempermudah dalam pemodelan beban angin (wind load) yang terjadi pada struktur yang berada diatas permukaan air laut, dengan memasukkan data-data yang diperlukan.

Adapun data yang menjadi acuan adal ah sebagai berikut :

Wind Speed : $34.7 \mathrm{~m} / \mathrm{s}, 100$ year (Storm)

Referensi Elevasi : $10.00 \mathrm{~m}$
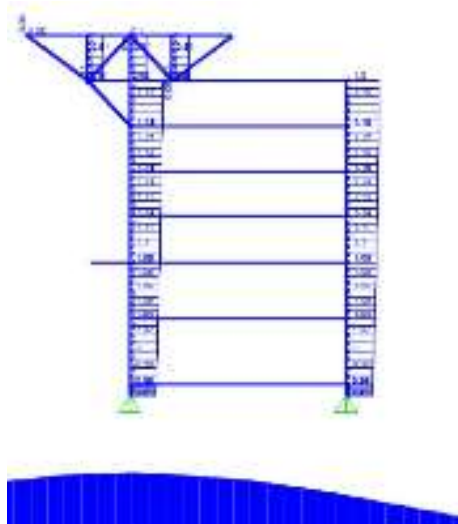

Gambar 2. Beban Angin diatas permukaan laut

Setelah didapat nilai beban angina yang bekerja pada tiap elevasi struktur, lalu disebarkan manjadi beban area yang mewakili pelat tembok pada modul.

\subsection{Pembebanan Akibat Pergerakan Kapal (Acceleration Load)}

Perhitungan beban akibat pergerakan kapal (acceleration load), beban sendiri struktur dihitung dan dikalikan dengan angka akselerasi kapal. Beban akibat pergerakan kapal ini diasumsikan sebagai beban aksial yang bekerja ditiap kolom struktur pada deck stool. Pada perhitungan beban akibat akselerasi digunakan pada yang merupakan data dengan satuan $(\mathrm{g})$ yang akan dikalikan dengan beban struktur sehingga mengakibatkan beban luar terhadap struktur. Data yang berkaitan dengan beban akibat pergerakan kapal dapat dilihat pada Tabel 4, Tabel 5 dan Tabel 6.
Tabel 4. Motion Criteria

\begin{tabular}{|l|c|c|}
\hline \multicolumn{1}{|c|}{ Motion } & Amplitude & Period \\
\hline Roll & $20 \mathrm{deg}$ & $10 \mathrm{sec}$ \\
\hline Pitch & $12.5 \mathrm{deg}$ & $10 \mathrm{sec}$ \\
\hline Heave & \multicolumn{2}{|c|}{$0.2 \mathrm{~g}$} \\
\hline
\end{tabular}

Tabel 5. Data Akselerasi

\begin{tabular}{cccc}
\hline Arah & surge(g) & sway(g) & heave(g) \\
\hline 0 & 0.03 & - & 0.03 \\
\hline $\mathbf{4 5}$ & 0.02 & 0.02 & 0.04 \\
\hline 90 & - & 0.11 & 0.13 \\
\hline 135 & 0.02 & 0.02 & 0.04 \\
\hline 180 & 0.01 & - & 0.02 \\
\hline $\mathbf{2 2 5}$ & 0.02 & 0.02 & 0.04 \\
\hline $\mathbf{2 7 0}$ & - & 0.11 & 0.13 \\
\hline $\mathbf{3 1 5}$ & 0.02 & 0.02 & 0.04
\end{tabular}

Tabel 6. Data Beban Akselerasi Struktur LQ

\begin{tabular}{|l|l|l|l}
\hline $\begin{array}{c}\text { Enivronm } \\
\text { ental Load } \\
\text { Direction }\end{array}$ & $\begin{array}{c}\text { Fx } \\
(\mathbf{k N})\end{array}$ & $\begin{array}{c}\mathbf{F y} \\
(\mathbf{k N})\end{array}$ & $\begin{array}{c}\mathbf{F z} \\
(\mathbf{k N})\end{array}$ \\
$0 \mathrm{deg}$ & -5153.7 & -39.4 & 25486.9 \\
\hline $45 \mathrm{deg}$ & -5275.2 & -8610.4 & 24134.4 \\
\hline $90 \mathrm{deg}$ & -169.8 & -23971 & 37217.1 \\
\hline $135 \mathrm{deg}$ & 5297.4 & -8739.7 & 41384.0 \\
\hline $180 \mathrm{deg}$ & 5004.1 & -26.3 & 38261.6 \\
\hline $225 \mathrm{deg}$ & 5281.4 & 8741.8 & 41422.6 \\
\hline $270 \mathrm{deg}$ & 143.6 & 23929.5 & 38171.5 \\
\hline $315 \mathrm{deg}$ & -5291.2 & 8636.7 & 24170.8 \\
\hline
\end{tabular}

\subsection{Model Beban}

Dalam analisis struktur living quarter, diterapkan beberapa pemodelan beban pada struktur. Untuk beban angin pada analisis kali ini beban tersebut mengenai wall plate pada struktur living quarter dan disebarkan secara merata menjadi beban area pada masing masing elevasi.

Dalam pemodelan beban mati dan hidup, digunakan asumsi beban area yang secara merata menyebar ke seluruh profil balok pada struktur. Dalam hal ini, berat sendiri struktur sudah terkalkulasi dengan sendirinya berdasarkan profil yang dipakai.

Dalam pemodelan beban akibat pergerakan kapal (acceleration load) didefinisikan sebagai beban terpusat yang bekerja di atas profil box yang menumpu struktur bangunan atau deck stool. 
Diasumsikan bahwa deck stool bergerak sesuai dengan pergerakan kapal sehingga menimbulkan gaya aksial di atasnya.

Langkah pertama untuk mengetahui kekuatan dari struktur adalah dengan analisis manual maupun dengan hasil analisis oleh program SAP2000. Profil yang dianalisis adalah profil yang memiliki rasio ultimate dan kapasitas yang mendekati angka 1. Gambar 3, Gambar 4 dan Gambar 5 merupakan pemodelan 3D dari kapal.

Hasil analisis dapat dilihat pada Gambar 6. Elemen struktur yang berwarna merah merupakan profil struktur dalam kondisi gagal atau overstress, warna jingga merupakan kondisi profil struktur sudah kritis tapi masih layak digunakan, warna kuning adalah kondisi mendekati kondisi kritis, warna hijau adalah kondisi layak atau aman, sedangkan warna biru berarti profil struktur sangat aman.
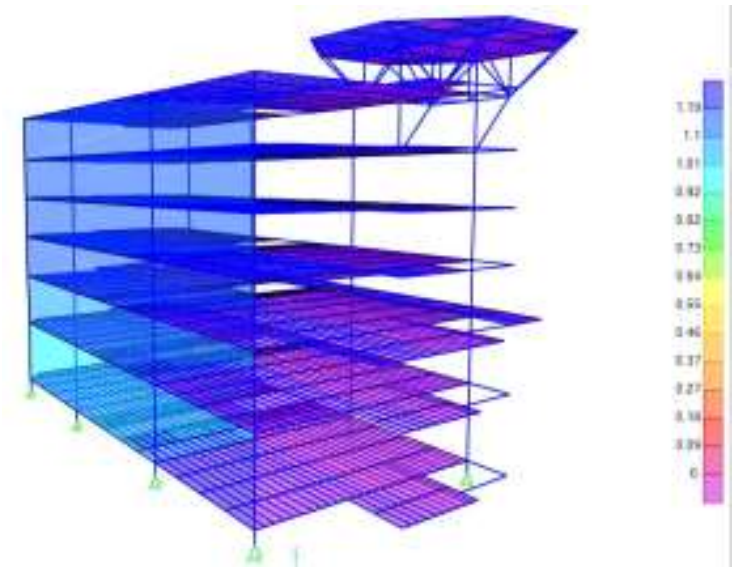

Gambar 3. Beban Angin pada Wall Plate

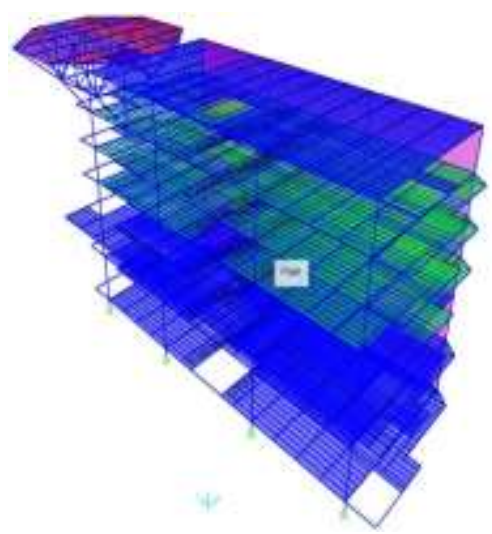

Gambar 4. Model Beban Mati dan Hidup

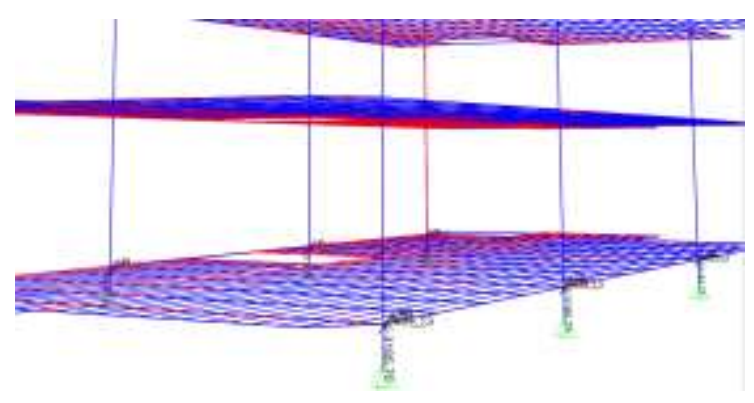

Gambar 5. Model Beban Akselerasi (270)

Pada analisis yang sudah dilakukan didapatkan profil yang mengalami momen terbesar dan rasio mendekati 1 adalah profil kolom CHS800Øx20, sedangkan untuk profil balok yang mendekati rasio 0.8 adalah HE800A. Dari hasil steel design /check of structure pada program SAP2000 dilihat profil yang memiliki rasio ultimate dan kapasitas mendekati 1 dari 8 kondisi arah pembebanan untuk digunakan dalam analisis manual menggunakan SNI dan AISC.

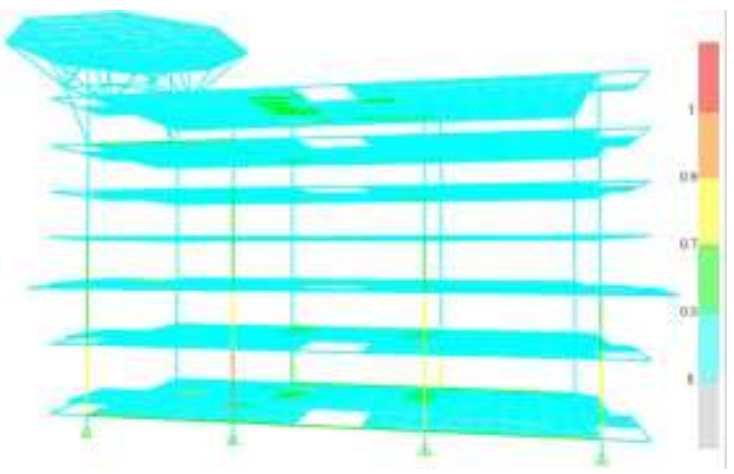

Gambar 6. Hasil Analisis Pada Kondisi Pembebanan Arah $270^{\circ}$

\subsection{Analisis Dengan AISC}

Setelah didapatkan data struktur momen, geser dan aksial maksimum pada profil melalui program SAP2000 didapatkan profil CHS800 $\varnothing \times 20$ dan HE800A memiliki rasio terbesar dibandingkan dengan profil lainnya yang terjadi pada kondisi arah pembebanan 270 derajat dimana didapatkan momen ultimate sebesar $2010 \mathrm{kNm}$, geser ultimare $756,6 \mathrm{kN}$, dan aksial ultimate sebesar $62,5 \mathrm{kN}$ untuk profil balok HE800A. Sedangkan pada profil kolom CHS800 $\varnothing \times 20$ didapat momen ultimate sebesar $1097 \mathrm{kNm}$, geser ultimate $362 \mathrm{kN}$, dan aksial ultimate -9209 $\mathrm{kN}$. 
Analisis profil HE800A (345 MPa) dengan AISC dibandingkan dengan hasil program SAP2000 sehingga perhitungan dilakukan sebagai berikut.

Aksi Kolom

$\mathrm{G}_{\mathrm{A}}=10$

$\mathrm{G}_{\mathrm{B}}=\frac{\sum\left(\frac{I}{L}\right) \text { kolom }}{\sum\left(\frac{I}{L}\right) \text { balok }}=\frac{2\left(\frac{.12620}{420}\right)}{\sum\left(\frac{372957}{1950}\right)}=0.3$

$\mathrm{k}_{\mathrm{x}}=1.7$

$\frac{K L}{r}=\frac{K x L}{r x}=\frac{1.8(19.5)}{0.324}=102$

$\mathrm{KL} / \mathrm{r}=102, \mathrm{Fcr}=160$ Mpa (Perbandingan

Kurva Fcr Mutu Baja ASTM-A992)

$\mathrm{Pn}=\mathrm{Ag} . \mathrm{fcr}=27810.160=444.9$ Ton $=4449$

$\mathrm{Kn}$

$\frac{P u}{\not N n}=\frac{62.5}{0.85 \times 4491}=0.01<0.2$

- Aksi Balok

$\lambda=\frac{B}{2 T f}=\frac{300}{2(26)}=5.76$

$\lambda \mathrm{p}=\frac{170}{\sqrt{F y}}=\frac{170}{\sqrt{345}}=9.15$

$\lambda \mathrm{r} \quad=\frac{370}{\sqrt{F y-F r}}=\frac{370}{\sqrt{345-115}}=24.4$

Karena $\lambda \leq \lambda$ p, penampang adalah kompak.

- Cek Penampang Badan

$\begin{array}{llll}\lambda & =\frac{h}{T w} & =\frac{800}{14} & =57.14 \\ \lambda \mathrm{p} & =\frac{1680}{\sqrt{F y}} & =\frac{1680}{\sqrt{345}} & =90.45 \\ \lambda \mathrm{r} & =\frac{2550}{\sqrt{F y}} & =\frac{2550}{\sqrt{345}} & =137.29\end{array}$

Karena $\lambda \leq \lambda$ p, penampang adalah kompak, lalu ditentukan katagori bentangnya.

$\mathrm{L}=0.75 \mathrm{~m}$

$\mathrm{Lp}=1.76 \mathrm{ry} \sqrt{\left(\frac{E}{f y}\right)}=2.85 \mathrm{~m}$

$\mathrm{X} 1=\frac{\pi}{S x} \sqrt{\frac{E G J A}{2}}=902.648 \mathrm{~kg} / \mathrm{cm}^{2}$

$\mathrm{X} 2=4\left(\frac{S x}{G J}\right)^{2} \frac{I w}{I y}=1.17 \times 10^{-7}$

$\mathrm{fL}=\mathrm{fy}-\mathrm{fr}=275 \mathrm{MPa}$

$\mathrm{Lr}=\operatorname{ry}\left[\frac{X 1}{f L}\right] \sqrt{1+\sqrt{1+X 2 f L^{2}}}=34.05 \mathrm{~m}$

Karena L $<$ Lp $<$ Lr maka termasuk katagori bentang pendek

$\phi b \mathrm{Mp}=\mathrm{Zx} . \mathrm{Fy}=(0.9) \quad 8421135.0 .345=2614.7 \mathrm{KN}$

$\phi b \mathrm{Mn}=2614.7 \mathrm{KN}$
- Perbesaran Momen

$\frac{K L}{r}=\frac{K x L}{r x}=\frac{1.8(19.5)}{0.324}=102$

$\mathrm{Cm}=0.6-0.4 \mathrm{M} 1 / \mathrm{M} 2=0.6-0.4 .1918 / 2010=$ 0.21

$\mathrm{Pe}=\frac{\pi^{2} \cdot E \cdot A g}{\left(k \cdot \frac{L}{r}\right)^{2}}=\frac{\pi^{2} \cdot 200000.27810}{(102)^{2}}=5280 \mathrm{KN}$

$\mathrm{B} 1=\frac{C m}{1-\frac{\Sigma P u}{\Sigma P e}}=\frac{0.21}{1-\frac{62}{5280}}=0.21<1 \quad ; \delta \mathrm{b}=1$

$\mathrm{B} 2=\frac{1}{1-\frac{\Sigma P u}{\Sigma P e}}=\frac{1}{1-\frac{62}{5280}}=1.01$

$\mathrm{Mn}=\mathrm{B} 1 \cdot \mathrm{Mnt}+\mathrm{B} 2 \cdot \mathrm{Mlt}=1 \cdot 1687+1 \cdot 01 \cdot 322=$ $2010 \mathrm{KNm}$

$\frac{P u}{\phi P n}=\frac{62}{4491}=0.01<0.2 \quad$ : Pakai persamaan H11b AISC

$\frac{P u}{2 \phi c P n}+\left(\frac{M u x}{\phi b M n x}+\frac{M u y}{\phi b M n y}\right)=\frac{0.01}{2}+\left(\frac{2010}{2614}+0\right)=$ $0.775<1$, Penampang memenuhi syarat analisis balok-kolom, sesuai dengan analisi program SAP2000.

- Cek Kuat Geser

Aw (Luas Penampang Badan) $=27810 \mathrm{~mm}^{2}$

$V u<\phi V n=0.6 \phi . A w . F y$

$\phi V n=0.6(0.9)(27810)(0.345)$

$5181 \mathrm{Kn}>\mathrm{Vu}=756.66 \mathrm{Kn}$

Profil kuat menahan gaya geser ultimate.

- Cek Lendutan

Wbaja $=78.5 \mathrm{Kn} / \mathrm{m}^{3}$

Aprofil $\quad=0.0278 \mathrm{~m}^{2}$

$\mathrm{ULS}=1.3$

$\mathrm{W}$ dead $=A \times$ Wbaja

$$
\begin{aligned}
& =0.0278 \times(78.50) \\
& =2.18 \mathrm{Kn} / \mathrm{m} \times 1.3 \\
& =2.836 \mathrm{Kn} / \mathrm{m}=2,836 \mathrm{~N} / \mathrm{mm}
\end{aligned}
$$

Wlive $=2.01 \mathrm{Kn} / \mathrm{m}=2010 \mathrm{~N} / \mathrm{mm}$

$\mathrm{E}=200000 \mathrm{MPa}, \mathrm{I}=126400000 \mathrm{~mm}^{4}$

$\Delta=52 \mathrm{~mm}$ pada jarak $10 \mathrm{~m}$ dari ujung profil

Lendutan ijin, $\Delta$ ijin $=\frac{\mathrm{L}}{240}=\frac{13125}{240}=54.667$ $\mathrm{mm}>\Delta=52 \mathrm{~mm}$, lendutan yang terjadi memenuhi syarat.

Analisis profil CHS800Øx20 (345 MPa) dengan AISC dibandingkan dengan hasil program SAP2000 sehingga perhitungan dilakukan sebagai berikut. 
- Cek Kapasitas Geser

$\mathrm{Ag}($ Luas Profil $)=49008 \mathrm{~mm}^{2}$

$V u<\phi V n=0.6 \phi . A g . F y$

$\phi V n=0.6(0.9)(49008)(0.345)=9130 \mathrm{Kn}>$

$\mathrm{Vu}=362 \mathrm{Kn}$

Profil kuat menahan gaya geser maksimum.

- Aksi Kolom

$\frac{K L}{r}=\frac{K x L}{r x}=\frac{1.3(6)}{0.275}=28.3$

$\lambda c=\frac{1}{\pi} \cdot \frac{k x \cdot l x}{r x} \cdot \sqrt{\frac{f y}{E}}=\frac{1}{\pi} \cdot 28 \cdot \sqrt{\frac{345}{200000}}=0.37$

$\omega=\frac{1.43}{1.6-0.67 . \lambda \mathrm{c}}=\frac{1.43}{1.6-0.67 .0,37}=1.05$

$\mathrm{Nn}=$ Ag.fcr $=49008.85(345 / 1.05)=16102 \mathrm{Kn}$

$\frac{N u}{\varnothing N n}=\frac{8638}{0.85 \times 15986}=0.63>0.2$

- Aksi Balok

$\lambda=\frac{D}{t}=\frac{800}{20}=40$

$\lambda \mathrm{p} \quad=\frac{0.7 E}{F y}=\frac{140000}{345}=405$

$\lambda \mathrm{r} \quad=\frac{0.31 E}{F y}=\frac{140000}{345}=149$

Karena $\lambda<\lambda$, penampang adalah kompak, lalu ditentukan katagori bentangnya.

$\mathrm{L}=6 \mathrm{~m}$

$\mathrm{Lp}=1.76$ ry $\sqrt{\left(\frac{E}{f y}\right)}=11.6 \mathrm{~m}$

Karena L $<$ Lp maka termasuk katagori bentang pendek

$\mathrm{Mn}=\mathrm{Mp}$

$\phi \mathrm{bMp}=\mathrm{Zx} . \mathrm{Fy}=0.9(0.345)(12170667)=$ 3778.92 Kn.m

\section{- Perbesaran Momen}

$\mathrm{KL} / \mathrm{r}=28, \mathrm{Fcr}=340 \mathrm{Mpa}$

(Perbandingan

Kurva Fcr Mutu Baja ASTM-A992)

$\phi c P n=0.85 x \mathrm{Ag} x \mathrm{~F} c \mathrm{r}$

$\phi c P n=0.85 \times 0.0490 \times 340000=14994 \mathrm{Kn}$

$\mathrm{Cm}=0.6-0.4 \mathrm{M} 1 / \mathrm{M} 2=0.6-0.4 .1161 / 1182=$ 0.20

$\mathrm{Pe}=\frac{\pi^{2} E A g}{\left(\frac{K L}{r}\right)^{2}}=\frac{\pi^{2} 200000000 \times 0.049}{(28)^{2}}=123469 \mathrm{Kn}$

$\mathrm{B} 1=\frac{\mathrm{Cm}}{1-\frac{\Sigma P u}{\Sigma P e}}=\frac{0.20}{1-\frac{8922}{123469}}=0.2<1 ; \quad \delta \mathrm{b}=1$

$\mathrm{B} 2=\frac{1}{1-\frac{\Sigma P u}{\Sigma P e}}=\frac{1}{1-\frac{8922}{123469}}=1.07($ Persamaan $\mathrm{C} 1-5$

AISC)
Momen total, $\mathrm{Mu}=\mathrm{B} 1 . \mathrm{Mnt}+\mathrm{B} 2 . \mathrm{Mlt}=$ $1.0(1070)+1.07(99.8)=1177$ Kn.m $\phi M n=0.9(0.345)(12170667)=3778.92 \mathrm{Kn} \cdot \mathrm{m}$ $\phi b M p=1.0 \times 3778.92=3778.92 \mathrm{Kn} . \mathrm{m}$

Untuk distribusi linear dengan nilai $\mathrm{M}=0$ pada salah satu ujungnya maka asumsi perhitungan $\mathrm{Cb}$ sebagai berikut :

$$
\begin{aligned}
\mathrm{Cb} & =\frac{12.5 \cdot M \max }{2.5 \cdot M \max +3 . M a+4 . M b+3 . M c} \\
= & \frac{12.5(1.0)}{2.5(1.0)+3(0.25)+4(0.5)+3(0.75)} \\
& =1.67
\end{aligned}
$$

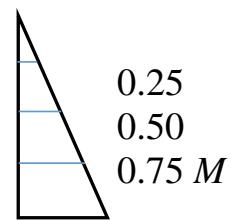

$\phi b M n x=1.67 x 3778.92=6310.79 \mathrm{Kn} \cdot \mathrm{m}$ $\phi b M p x$ pada distribusi linear dengan $\mathrm{M}=0$ memiliki nilai lebih besar dari $\phi b M n x$, diambil $\phi b M n x$ dengan nilai 3778.92 Kn.m .

$\frac{P u}{\phi c P n}=\frac{9209}{14494}=0.63>0.2 \quad: \quad$ persamaan H1-1a AISC

$\frac{P u}{\phi c P n}+\left(\frac{M u x}{\phi b M n x}+\frac{M u y}{\phi b M n y}\right)=0.63+\frac{8}{9}\left(\frac{1177}{3778}+\right.$ $0)=0.91<1$, Penampang memenuhi syarat kekuatan desain balok-kolom.

Analisis profil HE800A (345 MPa) dengan SNI dibandingkan dengan hasil program SAP2000 sehingga perhitungan dilakukan sebagai berikut.

\section{- Aksi Kolom}

$\mathrm{G}_{\mathrm{A}}=10$

$\mathrm{G}_{\mathrm{B}}=\frac{\sum\left(\frac{I}{L}\right) \text { kolom }}{\sum\left(\frac{I}{L}\right) \text { balok }}=\frac{2\left(\frac{.12620}{420}\right)}{\sum\left(\frac{372957}{1950}\right)}=0.3$

$\mathrm{k}_{\mathrm{x}}=1.7$

$\frac{K L}{r}=\frac{K x L}{r x}=\frac{1.8(19.5)}{0.324}=102$

$\lambda \mathrm{c}=\frac{1}{\pi} \cdot \frac{k x \cdot l x}{r x} \cdot \sqrt{\frac{f y}{E}}=\frac{1}{\pi} \cdot 102 \cdot \sqrt{\frac{345}{200000}}=1.35$

$\omega=1.25 \lambda \mathrm{c}^{2}=2.2$

$\mathrm{Nn}=$ Ag.fcr $=26072(345 / 2 \cdot 2)=408.8$ Ton $=$ $4088 \mathrm{Kn}$

$\frac{N u}{\varnothing N n}=\frac{60.42}{0.85 \times 4088}=0.017<0.2$ 
- Aksi Balok

$\lambda=\frac{B}{2 T f}=\frac{300}{2(26)}=5.76$

$\lambda \mathrm{p}=\frac{170}{\sqrt{F y}}=\frac{170}{\sqrt{345}}=9.15$

$\lambda \mathrm{r}=\frac{370}{\sqrt{F y-F r}}=\frac{370}{\sqrt{345-115}}=24.4$

Karena $\lambda \leq \lambda$ p, penampang adalah kompak.

- Cek Penampang Badan

$\begin{array}{ll}\lambda & =\frac{h}{T w}=\frac{800}{14}=57.14 \\ \lambda \mathrm{p} & =\frac{1680}{\sqrt{F y}}=\frac{1680}{\sqrt{345}}=90.45 \\ \lambda \mathrm{r} & =\frac{2550}{\sqrt{F y}}=\frac{2550}{\sqrt{345}}=137.29\end{array}$

Karena $\lambda \leq \lambda$, penampang adalah kompak, lalu ditentukan katagori bentangnya.

$\mathrm{L}=0.75 \mathrm{~m}$

$\mathrm{Lp}=1.76$ ry $\sqrt{\left(\frac{E}{f y}\right)}=2.85 \mathrm{~m}$

$\mathrm{X} 1=\frac{\pi}{S x} \sqrt{\frac{E G J A}{2}}=902.648 \mathrm{~kg} / \mathrm{cm}^{2}$

$\mathrm{X} 2=4\left(\frac{S x}{G J}\right)^{2} \frac{I w}{I y}=1.17 \times 10^{-7}$

$\mathrm{fL}=\mathrm{fy}-\mathrm{fr}=275 \mathrm{MPa}$

$\mathrm{Lr}=\operatorname{ry}\left[\frac{X 1}{f L}\right] \sqrt{1+\sqrt{1+X 2 f L^{2}}}=34.05 \mathrm{~m}$

Karena $\mathrm{L}<\mathrm{Lp}<\mathrm{Lr}$ maka termasuk katagori bentang menengah

$\phi b M p=Z x . F y=(0.9) 7995464.0 .345=2482.5$

$\mathrm{KN}$

$\phi b M n=2482.5 \mathrm{Kn} . \mathrm{m}$

- Perbesaran Momen

$\frac{K L}{r}=\frac{K x L}{r x}=\frac{1.8(19.5)}{0.324}=102$

$\mathrm{Cm}=0.6-0.4 \mathrm{M} 1 / \mathrm{M} 2=0.6-0.4 .680 / 1930=$ 0.46

$\mathrm{Nel}=\frac{\pi^{2} \cdot E \cdot A g}{\left(k \cdot \frac{L}{r}\right)^{2}}=\frac{\pi^{2} .200000 .26072}{(102)^{2}}=4950.8 \mathrm{KN}$

$\delta \mathrm{b}=\frac{C m}{1-\frac{\Sigma N u}{\Sigma N e l}}=\frac{0.46}{1-\frac{60.4}{4950}}=0.46<1 ; \delta \mathrm{b}=1$

$\delta s=\frac{1}{1-\frac{\Sigma N u}{\Sigma N e l}}=\frac{1}{1-\frac{60.4}{4950}}=1.01$

$\mathrm{Mn}=\delta \mathrm{b} . \mathrm{Mntu}+\delta \mathrm{s} . \mathrm{Mltu}=1.1625+1.01$.

$305.2=1933 \mathrm{KNm}$

$\frac{N u}{\phi N n}=\frac{60.9}{4088}=0.01<0.2 \quad: \quad$ persamaan

H1-1b AISC

$\frac{N u}{2 \phi c N n}+\left(\frac{M u x}{\phi b M n x}+\frac{M u y}{\phi b M n y}\right)=\frac{0.01}{2}+\left(\frac{1933}{2482.5}+\right.$

$0)=0.783<1$, Penampang memenuhi syarat analisis balok-kolom, sesuai dengan analisi program SAP2000.
- Cek Kuat Geser

Aw (Luas Penampang Badan $)=26072 \mathrm{~mm}^{2}$

$V u<\phi V n=0.6 \phi . A g . F y$

$\phi V n=0.6(0.9)(26072)(0.345)$

$4857 \mathrm{Kn}>\mathrm{Vu}=730.87 \mathrm{Kn}$

Penampang kuat menahan gaya geser maksi mum.

- Cek Lendutan

Wbaja $=7850 \mathrm{Kg} / \mathrm{m}^{3}=78.5 \mathrm{Kn} / \mathrm{m}^{3}$

Aprofil $\quad=0.0278 \mathrm{~m}^{2}$

$\mathrm{ULS}=1.3$

$\mathrm{W}$ dead $=A \quad x$ Wbaja

$=0.0278 \times(78.50)$

$=2.18 \mathrm{Kn} / \mathrm{m} \times 1.3$

$=2.836 \mathrm{Kn} / \mathrm{m}=2,836 \mathrm{~N} / \mathrm{mm}$

Wlive $=2.01 \mathrm{Kn} / \mathrm{m}=2010 \mathrm{~N} / \mathrm{mm}$

$\mathrm{E}=200000 \mathrm{MPa}, \mathrm{I}=126400000 \mathrm{~mm}^{4}$

$\Delta=52.3 \mathrm{~mm}$ pada jarak $10 \mathrm{~m}$ dari ujung profil Lendutan ijin, $\Delta$ ijin $=\frac{\mathrm{L}}{240}=\frac{13125}{240}=54.667$ $\mathrm{mm}>\Delta=52.3 \mathrm{~mm}$, lendutan yang terjadi memenuhi syarat.

Analisis profil CHS800Øx20 (345 MPa) dengan SNI dibandingkan dengan hasil program SAP2000 sehingga perhitungan dilakukan sebagai berikut.

- Cek Kapasitas Geser

Ag (Luas Profil) $=49008 \mathrm{~mm}^{2}$

$V u<\phi V n=0.6 \phi . A g . F y$

$\phi V n=0.6(0.9)(49008)(0.345)=9130 \mathrm{Kn}$

$>\mathrm{Vu}=354 \mathrm{Kn}$

Penampang kuat menahan gaya geser maksimum.

- Aksi Kolom

$\frac{K L}{r}=\frac{K x L}{r x}=\frac{1.3(6)}{0.275}=28.3$

$\lambda \mathrm{c}=\frac{1}{\pi} \cdot \frac{k x \cdot l x}{r x} \cdot \sqrt{\frac{f y}{E}}=\frac{1}{\pi} \cdot 28 \cdot \sqrt{\frac{345}{200000}}=0.37$

$\omega=\frac{1.43}{1.6-0.67 . \lambda \mathrm{c}}=\frac{1.43}{1.6-0.67 .0,37}=1.05$

$\mathrm{Nn}=$ Ag.fcr $=49008.85(345 / 1.05)=16102 \mathrm{Kn}$

$\frac{N u}{\varnothing N n}=\frac{8638}{0.85 \times 15986}=0.63>0.2$

- Aksi Balok

$\lambda \quad=\frac{D}{t}=\frac{800}{20}=40$

$\lambda \mathrm{p} \quad=\frac{0.7 E}{F y}=\frac{140000}{345}=405$

$\lambda \mathrm{r} \quad=\frac{0.31 E}{F y}=\frac{140000}{345}=149$ 
Karena $\lambda \leq \lambda p$, penampang adalah kompak, lalu ditentukan katagori bentangnya.

$\mathrm{L}=6 \mathrm{~m}$

$\mathrm{Lp}=1.76 \mathrm{ry} \sqrt{\left(\frac{E}{f y}\right)}=11.6 \mathrm{~m}$

Karena L < Lp maka termasuk katagori bentang pendek

$\mathrm{Mn}=\mathrm{Mp}$

$\phi b M p=Z x . F y=0.9(0.345)(12170667)=$ 3778.92 Kn.m

- Perbesaran Momen

$\phi c P n=0.85 x \mathrm{Ag} x \mathrm{Fcr}$

$\phi c P n=0.85 \times 0.0490 \times 331000=13687 \mathrm{Kn}$

$\mathrm{Cm}=0.6-0.4 \mathrm{M} 1 / \mathrm{M} 2=0.6-0.4 .1056 / 1069=$ 0.20

$\mathrm{Nel}=\frac{\pi^{2} \cdot E \cdot A g}{\left(k \cdot \frac{L}{r}\right)^{2}}=\frac{\pi^{2} .200000 .49008}{(28)^{2}}=123469 \mathrm{KN}$

$\delta \mathrm{b}=\frac{C m}{1-\frac{\Sigma N u}{\Sigma N e l}}=\frac{0.20}{1-\frac{8873}{123469.8}}=0.52<1 \quad ; \delta \mathrm{b}=$

1.0

$\delta s=\frac{1}{1-\frac{\Sigma N u}{\Sigma N e l}}=\frac{1}{1-\frac{8873}{123469}}=1.07$

Total momen ,

Mux = B1.Mnt + B2.Mlt = 1.0(983.1) +

$1.07(96.9)=1087.5$ Kn.m

$\phi M n=0.9(0.345)(12170667)=3778.92 \mathrm{Kn} . \mathrm{m}$

$\phi b M p=3778.92 \mathrm{Kn} . \mathrm{m}$

Untuk distribusi linear dengan nilai $\mathrm{M}=0$ pada salah satu ujungnya maka asumsi perhitungan $\mathrm{Cb}$ sebagai berikut :

$$
\begin{gathered}
\mathrm{Cb}=\frac{12.5 M \max }{2.5 M \cdot \max +3 \cdot M a+4 . M b+3 . M c} \\
=\frac{12.5(1.0)}{2.5(1.0)+3(0.25)+4(0.5)+3(0.75)} \\
=1.67
\end{gathered}
$$

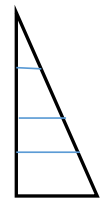

$0.25 M$

$0.50 M$

$0.75 M$

$\phi b M n x=1.67 x 3778.92=6310.79 \mathrm{Kn} . \mathrm{m}$ $\phi b M p x$ pada distribusi linear dengan $\mathrm{M}=0$ memiliki nilai lebih besar dari $\phi b M n x$ maka diambil nilai $\phi b M n x$ dengan nilai 3778.92 Kn.m.

$\frac{N u}{\phi N n}=\frac{8873}{13687}=0.64>0.2$

: Pakai persamaan H1-1a AISC
$\frac{N u}{\phi c N n}+\frac{8}{9}\left(\frac{M u x}{\phi b M n x}+\frac{M u y}{\phi b M n y}\right)=0.64+$ $\frac{8}{9}\left(\frac{1087.5}{3778.9}+0\right)=0.89<1$, Profil memenuhi syarat analisis balok-kolom, sesuai dengan analisis program SAP2000.

\section{KESIMPULAN}

Berdasarkan analisis yang dilakukan pada struktur living quarter pada floating production system di perairan Indonesia pada saat kondisi transportasi didapatkan hasil sebagai berikut :

1. Berdasarkan analisis, perilaku struktur balok yang terjadi pada beberapa profil seperti profil balok HE800A dan profil kolom $\varnothing 800 x 20$ kuat menahan beban beban yang bekerja pada kondisi transportasi dan sama halnya dengan menggunakan profil dan standart SNI pada kondisi dan pembebanan yang sama dengan standar AISC dan profil EURO.

2. Struktur living quarter mampu menahan beban - beban yang bekerja di lapangan dalam kondisi ekstrin, hal tersebut telah dijelaskan pada analisis secara manual dengan pedoman baja AISC dan SNI dimana beberapa kondisi seperti momen, gaya geser dan gaya aksial terbesar yang terjadi pada penampang HE800A dan Circular Hollow $\varnothing 800 \times 20$ mampu ditahan oleh kedua profil tersebut. Selain itu, dalam analisis balok-kolom kedua profil tersebut terbukti kuat menahan beban yang terjadi dengan angka rasio 0.779 pada profil HE800A dan 0.919 pada Circular Hollow $\varnothing 800 \times 20$ dimana kedua rasio tersebut mendekati kondisi kritis tetapi tidak melebihi angka 1 yang merupakan kriteria ijin.

\section{DAFTAR PUSTAKA}

[1] American Institute of Steel Construction, "Manual of Steel Construction, LRFD vol.1" ,2 $2^{\text {nd }}$ ed.

[2] American Institute of Steel Construction, "Manual of Steel Construction, LRFD vol.2" ,2 $2^{\text {nd }}$ ed.

[3] American Petroleum Institute, "Planning, Designing, and Constructing Fixed Offshore Platforms-Working Stress Design”, $22^{\text {nd }}$ ed.

[4] American Petroleum Institute, "Planning, Designing, and Constructing Floating Production Systems", $2^{\text {nd }}$ ed.

[5] Standar Nasional Indonesia-03-1729-2002. 